\title{
A PRODUÇÃO DE ERVA-MATE: UM ESTUDO DA DINÂMICA PRODUTIVA NOS ESTADOS DO SUL DO BRASIL
}

\section{Leticia Andrea Chechi ${ }^{1}$, Glauco Schultz ${ }^{2}$}

${ }^{1}$ Engenheira Florestal, Mestre e Doutoranda em Desenvolvimento Rural, Universidade Federal do Rio Grande do Sul (UFRGS), (leti_chechi@hotmail.com,) Porto Alegre, RS - Brasil.

${ }^{2}$ Engenheiro Agrícola, Mestre e Doutor em Agronegócios, Universidade Federal do Rio Grande do Sul (UFRGS) Porto Alegre, RS - Brasil.

Recebido em: 08/04/2016 - Aprovado em: 30/05/2016 - Publicado em: 20/06/2016

DOI: 10.18677/Enciclopedia_Biosfera_2016_002

\begin{abstract}
RESUMO
A erva-mate é o principal produto florestal não-madeireiro cultivado nos estados do sul do Brasil, representando uma importante fonte de renda aos pequenos produtores. O chimarrão é o principal produto comercializado nesse setor, que vem apresentando alterações na dinâmica produtiva nos últimos anos, onde o estado do Rio Grande do Sul vem perdendo seu espaço no mercado, principalmente para o estado do Paraná. Neste contexto, esse estudo objetiva compreender a dinâmica de produção da erva-mate nos três estados do sul do Brasil, através da análise de dados produtivos de 1990 a 2014, e entrevistas com agentes ligados ao setor. Os resultados apresentam a influência da mecanização na produção e distribuição da erva-mate no Rio Grande do Sul, bem como o crescimento da produção no estado do Paraná, principalmente pela preservação dos ervais nativos e sua contínua exploração. As características diferenciadas de produção e foco de mercado, também podem influenciar no aumento da representatividade do Paraná na produção de erva-mate nacional. Por fim, a ausência de mecanismos de regulação ou garantia de preço ao produtor, e os possíveis desequilíbrios nessa cadeia, são elementos que necessitam análises adicionais em trabalhos futuros.
\end{abstract}

PALAVRAS-CHAVE: Cadeia produtiva, dinamcia de produção, erva-mate.

\section{DINAMICS OF PRODUCTION OF YERBA MATE IN THE STATES OF SOUTH BRAZIL}

\begin{abstract}
Yerba mate is the main non-timber forest products grown in the southern states of Brazil, representing an important source of income for small producers. The mate is the main product marketed in this sector, which has shown changes in the production dynamics in recent years, where the state of Rio Grande do Sul has lost its space in the market, especially for the state of Paraná.. In this context, this study search to understand the dynamics of yerba mate production in the three south states of Brazil,
\end{abstract}


through the production data analysis from the 1990 to 2014, and interviews with actors from the sector. The results show the influence of mechanization in the production and distribution of yerba mate in Rio Grande do Sul, as well as the growth production in the state of Paraná, especially through the preservation of native yerba mate and their continued exploitation. The distinctive characteristics of production and market focus can also influence the increased representation of Paraná in the production of national yerba mate. Lastly, the absence of regulatory mechanisms or price guarantee to the producer, and the possible imbalances in the chain, are elements that need further analysis in future work.

KEYWORDS: Productive c hain, production dynamics, yerba mate.

\section{INTRODUÇÃO}

Brasil possui aproximadamente $54,4 \%$ de seu território coberto por florestas naturais e plantadas, o que representa mais de 463 milhões de hectares. Desta área, 456 milhões de hectares são florestas naturais e 7,2 milhões de hectares de florestas plantadas, considerando ano base 2011/2012. O Valor Bruto da Produção (VPB) obtido pelo setor em 2012 foi de 56,3 bilhões, arrecadando 7,6 bilhões em tributos, o que representa 0,5\% da arrecadação nacional (ABRAF, 2013). De acordo com MEDRADO et al. (2005), o reconhecimento do setor florestal na economia brasileira seria maior se fossem consideradas as vantagens da produção não madeireira, de produtos como da castanha-do-Brasil, a borracha e a erva-mate.

A erva-mate, botanicamente conhecida como Ilex paraguariensis St. Hill, advém naturalmente do Brasil, Paraguai e Argentina, todavia, mais de $80 \%$ do total situa-se no bioma brasileiro Mata Atlântica. No Brasil, o cultivo ocorre a partir da porção centro-oeste do Rio Grande do Sul e adentra no estado de Santa Catarina. Avançando por este estado, chega ao Paraná, onde a área de ocorrência da produção ervateira se situa na região centro-sul e segue para as porções oeste e nordeste do estado paranaense, até atingir o sul do Mato Grosso do Sul e pequena porção da região sudoeste de São Paulo (OLIVEIRA \& ROTTA, 1985).

Mesmo com a expansão desta cadeia produtiva nos últimos anos, o mercado de erva-mate se limita à região Sul do país, apresentando o Rio Grande do Sul como líder em termos de consumo e de oferta do produto, detendo cerca de $62 \%$ da produção nacional e consumindo $43,6 \%$ desta. O aumento da produção nos estados do Paraná, Santa Catarina e Mato Grosso do Sul fez com que o Rio Grande do Sul perdesse participação relativa na produção de erva-mate nacional (SINDIMATERRS, 2013; IBGE, 2013).

Em ambos os estados a economia ervateira destaca-se historicamente como atividade produtiva e comercial e pela sua relevância cultural. Devido às suas diversas utilizações como matéria-prima, representa uma das espécies arbóreas naturais de expressiva significância para o cenário socioeconômico de diversos municípios dos estados do Sul do Brasil, principalmente para os pequenos produtores rurais (BALZON, et al., 2004).

Considerando a sua importância no sul do Brasil e a oscilação da produção nos estados, este estudo tem por objetivo compreender a dinâmica de produção da erva-mate nos três estados do sul do Brasil, através da análise de dados de 1990 a 2014, e entrevistas com agentes ligados ao setor. 


\section{MATERIAL E MÉTODOS}

Considerando a classificação de GIL (2007), o método da pesquisa, quanto aos objetivos, se caracteriza como descritivo, objetivando apresentar a dinâmica de produção de erva-mate nos estados do Rio Grande do Sul, Santa Cataria e Paraná de 1990 até 2014.

De acordo com TRIVIÑOS (1987), a pesquisa descritiva exige uma série de informações do pesquisador, possibilitando descrever os fatos e fenômenos de determinada realidade. Ainda, podem se estabelecer relações entre variáveis, buscando identificar e comparar determinados aspectos (MALHOTRA, 2010).

Foram realizadas as coletas dos seguintes dados secundários: produção de erva-mate (folha verde/toneladas) nacional, por estado e por município; área colhida (hectares); número de municípios produtores; área de cultivo da erva-mate (mais de 50 pés); número de ervateiras por estado. Estes dados foram compilados a partir dos sítio eletrônico do Sistema IBGE de Recuperação Automática (SIDRA), pertencente ao Instituto Brasileiro de Geografia e Estatística (IBGE).

Além da revisão bibliográfica sobre a produção de erva-mate no Brasil e na região sul para interpretar os dados, foram realizadas entrevistas com agentes ligados ao setor ervateiro no estado do Rio Grande do Sul, nas cidades de Arvorezinha, llópolis e Venâncio Aires; Paraná, em São Mateus do Sul; e Santa Catarina, nos municípios de Canoinhas e Chapecó. O contato inicial se deu através dos sindicatos do setor de cada estado.

Foram dez agentes entrevistados, sendo quatro do Rio Grande do Sul, quatro de Santa Catarina e dois do Paraná. Estes possuem ligação com o setor ervateiro através das mais diversas organizações, das quais cita-se: Instituto Brasileiro da Erva-Mate (IBRAMATE), Associação dos Amigos da Erva-Mate do Polo do Alto do Vale do Taquari (AA Erva-Mate), Sindicato da Indústria do Mate (SINDIMATE RS/SC/PR), Empresa de Assistência Técnica e Extensão Rural (EMATER/RS), Empresa de Pesquisa Agropecuária e Extensão Rural de Santa Catarina (EPAGRI), e empresas privadas.

A análise e a interpretação do material qualitativo foi realizada através da análise de conteúdo do tipo categorial, onde foram criadas as principais categorias de análise da pesquisa, reduzindo o volume de dados. Nesta etapa ocorreu a simplificação, seleção e focalização em categorias de acordo com os temas ou padrões definidos nos objetivos da pesquisa. Após essa etapa, procedeu-se com a descrição das narrativas dos entrevistados que compõem as categorias criadas. Por fim, procedeu-se com a interpretação do conteúdo, a verificação do significado dos dados, seus padrões e explicações (APPOLINÁRIO, 2011).

Para tabulação e análise dos dados foram utilizados os programas Microsoft Office Excel e o software SPSS (Statistical Package for Social Sciences) e seus recursos de cálculos, recodificação dos dados, análises e representações gráficas.

\section{RESULTADOS E DISCUSSÃO}

A erva-mate representa um dos principais Produtos Florestais não Madeireiros (PFNM) cultivados no Brasil e da Argentina. Uma diferença entre os dois grandes países produtores refere-se à origem, de ervais nativos ou ervais cultivados, característica que apresenta diferenças técnicas e econômicas na produção e comercialização desse produto. $\mathrm{Na}$ Argentina, grande parte dos ervais são 
cultivados, a pleno sol, diferentemente do Brasil, onde existem grandes áreas com ervais nativos (MACCARI JUNIOR et al., 2006).

Mesmo mantendo áreas de ervais nativos, a produção de erva-mate no Brasil sofreu alterações com a mecanização agrícola na década de 1970. Os subsídios e os preços mínimos de garantia para culturas anuais determinados pelo governo incentivaram o plantio de soja e trigo, e com isso, a erradicação de ervais nativos. $O$ sistema produtivo da erva-mate manteve-se então concentrado em pequenos produtores, utilizando-se da mão de obra familiar para a produção (RUCKER \& ORTIGARA, 2003).

A erradicação de ervais nativos na década de 70 é mencionada pelos agentes locais entrevistados. De acordo com os mesmos o desenvolvimento da cadeia de commodities agrícolas e a mecanização no meio rural fez com que muitos agricultores substituíssem os ervais por plantios de soja, milho e trigo. Essa transformação se deu de forma generalizada no sul do Brasil, permanecendo ervais principalmente em regiões onde o terreno não possibilitava a mecanização.

\footnotetext{
$\mathrm{Na}$ década de 70 muitos ervais forram arrancados para plantio de soja, principalmente nas áreas que podiam ser mecanizadas. A erva-mate ficou nas áreas de terrenos acidentados. Isso acabou gerando os polos de produção de erva-mate no Rio Grande do Sul (Agente 2).
}

No ano de 2014, a produção brasileira foi de 602.484 toneladas de erva-mate, em uma área colhida de 70.820 hectares, alcançando um rendimento médio de 8,5 toneladas por hectare. Em uma série temporal é possível observar que a área colhida no Brasil era de 8.494 hectares em 1990, aumentando para 69.029 no ano de 2000 e chegando em 2014 a 70.820 hectares (IBGE, 2014). Mesmo em uma trajetória de crescimento, o agente 3 menciona oscilações da área colhida de ervamate, segundo ele, relacionada ao preço pago pela erva-mate ao produtor rural.

\footnotetext{
A produção de erva-mate passa por ciclos. A falta da matéria-prima, e o aumento do preço estimulando novos plantios. Em três, quatro anos, quando esses começam a ser colhidos, há uma sobra do produto, e o preço cai $[. .$.$] trabalho com erva-mate há muito tempo, isso se repete, estamos$ vivendo isso agora (Agente 3 ).
}

A oscilação de área colhida de erva-mate influencia na produção de matériaprima, que se concentra na região sul do Brasil, havendo uma pequena produção no estado do Mato Grosso do Sul. Como se observa na Figura 1, o Rio Grande do Sul apresenta uma trajetória ascendente, com períodos de menor produção de 1990 a 1992 e no ano de 1996. O estado do Paraná tem um grande aumento na produção de erva-mate a partir do ano de 1997, chegando a um pico de produção no ano de 2001, quando ultrapassa o Rio Grande do Sul. Após 2001 a produção decai, voltando a crescer em 2004, e posteriormente, no ano de 2011. O estado de Santa Catarina, mesmo com taxas crescentes de produção, mantém uma trajetória mais estável em relação aos outros dois estados. 


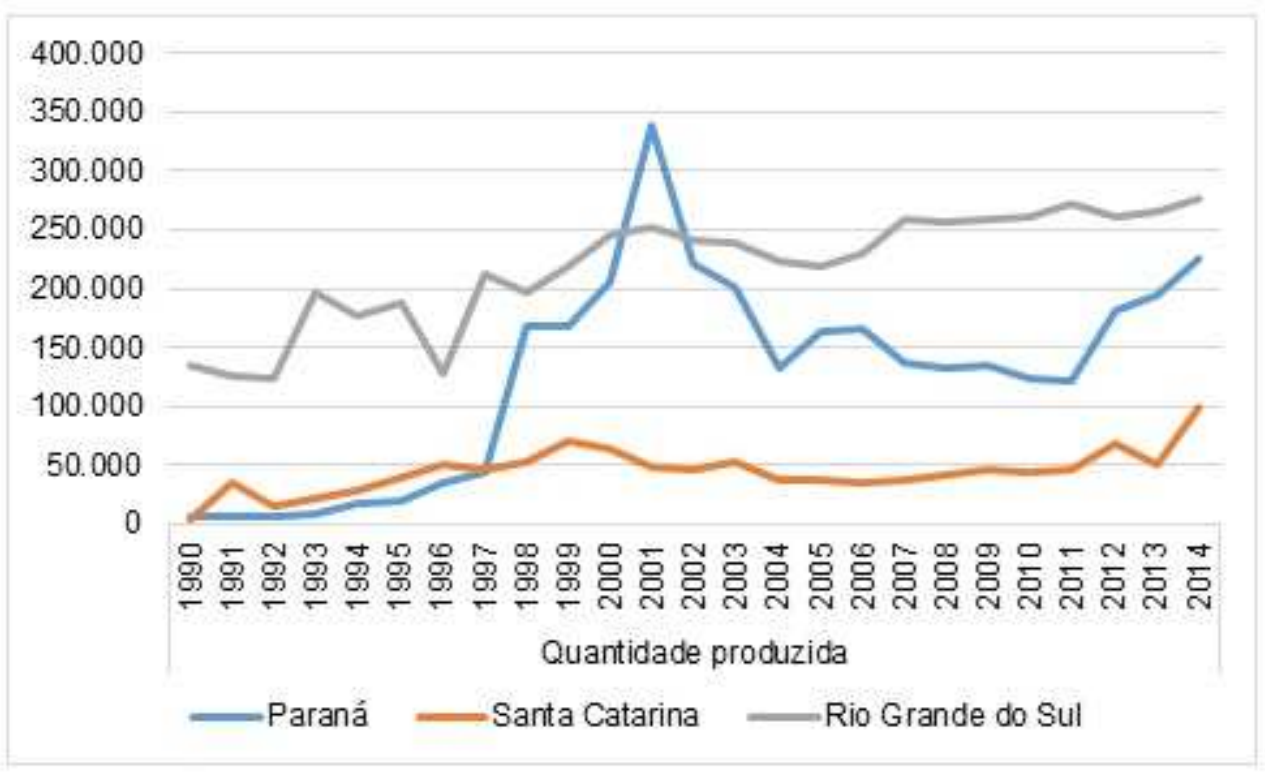

FIGURA 1: Quantidade de erva-mate produzida (toneladas de folha verde) nos três estados do sul do Brasil, de 1990 a 2014.

Fonte: Adaptado de IBGE (2014).

É importante ressaltar que os estados do sul do Brasil apresentam características de mercado diferenciadas. A produção de erva-mate no Rio Grande do Sul se destina principalmente ao mercado interno, com a erva-mate verde moída. Já nos estados do Paraná e Santa Catarina, há um redirecionamento da produção para erva-mate cancheada e envelhecida, atendendo as exportações, principalmente para o mercado Uruguaio. De acordo com o agente 5, as empresas do Paraná detêm cerca de $70 \%$ do mercado de erva-mate do Uruguai.

Referente a participação dos estados na produção nacional de erva-mate, essa modificou-se ao longo do tempo nos estados do sul do Brasil, como pode-se observar na Tabela 1. Em 1990 o Rio Grande do Sul era responsável por 92,5\% da produção de erva-mate brasileira, onde 135.970 toneladas de erva-mate eram produzidas em 170 municípios do estado. No ano 2000, houve um perceptível incremento da produção e também de municípios produtores, entretanto a participação do Rio Grande do Sul no total nacional reduziu: o estado produziu $46,8 \%$ da erva-mate do Brasil, em 280 municípios. Em 2010 chegou a um percentual de $60,5 \%$ do total nacional, e no ano de 2014 reduziu para $45,8 \%$ da erva-mate brasileira com 219 municípios produtores, representando 44,1\% dos municípios do estado.

A produção no Rio Grande do Sul divide-se em seis polos ervateiros, sendo eles: Planalto Missões, Alto Uruguai, Nordeste Gaúcho, Alto Taquari, Vale do Taquari e Canguçu. Essa denominação originou-se com a criação e efetivação do Programa Florestal RS (Decreto № 47.175, de 14 de abril de 2010) e a formalização do "Projeto de revitalização dos polos ervateiros do Rio Grande do Sul". Os 
municípios produtores estão localizados na região centro-superior do estado, principalmente no norte e no noroeste.

TABELA 1 - Quantidade de erva-mate (folha verde/ton.) produzida pelos estados e percentual da produção em relação ao Brasil (1990-2014).

\begin{tabular}{c|c|c|c|c|c|c|c}
\hline Ano & Brasil & RS & $\%$ & PR & $\%$ & SC & $\%$ \\
\hline 1990 & 147.072 & 135.970 & 92,5 & 6.106 & 4,2 & 4.996 & 3,4 \\
2000 & 522.019 & 244.477 & 46,8 & 206.188 & 39,5 & 63.203 & 12,1 \\
2010 & 430.305 & 260.413 & 60,5 & 123.132 & 28,6 & 43.266 & 10,1 \\
2014 & 602.484 & 276.232 & 45,8 & 225.078 & 37,4 & 98.519 & 16,4 \\
\hline
\end{tabular}

Fonte: Adaptado IBGE (2014).

No estado do Paraná, segundo maior produtor de erva-mate no Brasil, no ano de 1990 haviam 34 municípios produzindo erva-mate, sendo responsável por 4,2\% da produção nacional. Com 165 municípios, no ano de 2000 o Paraná foi responsável por 39,5\% da produção nacional, e no ano de 2014 produziu $37,4 \%$ da erva-mate brasileira em 102 municípios do estado, o que representa 25,5\% do total de municípios. É importante ressaltar que no ano de 2001 o Paraná ultrapassou o Rio Grande do Sul, produzindo $52,5 \%$ da erva-mate brasileira, enquanto que naquele ano o percentual de participação do Rio Grande do Sul no total nacional foi de $39 \%$.

O estado de Santa Catarina em 1990 apresentava pouca participação na produção de erva-mate a nível nacional, com apenas 21 municípios produtores. No ano de 2000 Santa Catarina produziu 12,1\% da erva-mate brasileira, diminuindo para $10,1 \%$ no ano de 2010, chegando em 2014 com uma participação de 16,4\% com 98 municípios produtores, 33,2\% dos municípios do estado.

Como pode-se observar na Tabela 1, o Rio Grande do Sul perde representatividade na produção de erva-mate nacional, enquanto o estado do Paraná amplia sua participação no cenário produtivo nacional. Esse fato é mencionado por MACCARI JUNIOR et al. (2006), e ainda, que no Paraná aproximadamente $80 \%$ dos ervais são nativos. Ocorrendo em consórcio com Araucária, se ampliou a exploração da erva-mate com o passar dos anos, sendo visualizada pelos produtores como uma fonte de renda. Já no Rio Grande do Sul, de acordo com os mesmos autores, aproximadamente $80 \%$ dos ervais são plantados, sendo os nativos substituídos por culturas anuais na década de 1970.

Outro elemento mencionado pelo agente 6 , do Paraná, é que a legislação ambiental deste estado foi mais restritiva do que no estado do Rio Grande do Sul, não possibilitando o arranquio de ervais nativos. Desta forma, os agricultores que já exploravam a folha para consumo próprio, ampliaram a extração para comercialização.

\footnotetext{
Aqui no Paraná a legislação ambiental favoreceu muito o setor ervateiro, restringindo o corte de araucária, e também da erva-mate, que crescem consorciadas nessa região [...] os ervais nativos foram mantidos, e cada vez mais explorados pelos agricultores, levando o estado do Paraná a uma posição de destaque na produção de erva-mate no Brasil.
}

Nos anos de 2000 e 2010, o município maior produtor de erva-mate do Brasil era do estado do Paraná, São Mateus do Sul (Tabela 2). De maneira detalhada, ENCICLOPÉDIA BIOSFERA, Centro Científico Conhecer - Goiânia, v.13 n.23; p. 21 2016 
pode-se observar na tabela que no ano de 2000, São Mateus do Sul - PR foi seguido por Fontoura Xavier - RS e Venâncio Aires - RS no ranking de produção de erva-mate. Já no ano de 2010, llópolis - RS que não estava presente entre os dez maiores produtores no ano de 2000, é o maior produtor de erva-mate do Brasil no ano de 2010, acompanhando de outros dois municípios do Rio Grande do Sul e dois do Paraná.

Os dados mais recentes, do ano de 2014 mostram São Mateus do Sul - PR como maior produtor de erva-mate do Brasil, seguido por llópolis - RS e Arvorezinha - RS, municípios próximos no Vale do Taquari. O município de São Mateus do Sul, assim como a região sul do estado do Paraná, tem sua história marcada pela extração da madeira e da erva-mate, de acordo com os agentes 5 e 6.

TABELA 2 - Municípios com a maior produção de erva-mate nos anos de 2000, 2010 e 2014 no Brasil.

\begin{tabular}{|c|c|c|c|c|c|}
\hline \multicolumn{6}{|c|}{ Ano } \\
\hline \multicolumn{2}{|c|}{2000} & \multicolumn{2}{|c|}{2010} & \multicolumn{2}{|c|}{2014} \\
\hline Município & $\begin{array}{l}\text { Produção } \\
\text { (ton) }\end{array}$ & Município & $\begin{array}{l}\text { Produção } \\
\text { (ton) }\end{array}$ & Município & $\begin{array}{l}\text { Produção } \\
\text { (ton) }\end{array}$ \\
\hline $\begin{array}{l}\text { São Mateus } \\
\text { do Sul - PR }\end{array}$ & 40.000 & Ilópolis - RS & 53.100 & $\begin{array}{l}\text { São Mateus } \\
\text { do Sul - PR }\end{array}$ & 62.000 \\
\hline $\begin{array}{c}\text { Fontoura } \\
\text { Xavier - RS }\end{array}$ & 23.400 & $\begin{array}{c}\text { Arvorezinha - } \\
\text { RS }\end{array}$ & 38.000 & llópolis - RS & 59.000 \\
\hline $\begin{array}{l}\text { Venâncio } \\
\text { Aires - RS }\end{array}$ & 20.790 & $\begin{array}{c}\text { Cruz } \\
\text { Machado - } \\
\text { PR }\end{array}$ & 29.610 & $\begin{array}{c}\text { Arvorezinha - } \\
\text { RS }\end{array}$ & 50.000 \\
\hline $\begin{array}{c}\text { Arvorezinha - } \\
\text { RS }\end{array}$ & 18.900 & $\begin{array}{l}\text { Palmeira das } \\
\text { Missões - RS }\end{array}$ & 18.200 & $\begin{array}{c}\text { Cruz } \\
\text { Machado - } \\
\text { PR }\end{array}$ & 45.000 \\
\hline $\begin{array}{c}\text { Cruz } \\
\text { Machado - } \\
\text { PR }\end{array}$ & 17.000 & $\begin{array}{c}\text { General } \\
\text { Carneiro - PR }\end{array}$ & 14.900 & $\begin{array}{c}\text { General } \\
\text { Carneiro - } \\
\text { PR }\end{array}$ & 24.040 \\
\hline
\end{tabular}

Fonte: Adaptado IBGE (2014).

Já no Rio Grande do Sul, de acordo com o agente 1, a região alta do Vale do Taquari se destaca na produção de erva-mate no Rio Grande do Sul, e também no contexto nacional, pelo relevo acidentado, presença da agricultura familiar e condições ambientais, como solo e clima, que fazem a erva-mate proveniente desta região apresentar um sabor diferenciado.

A expressividade do setor também pode ser visualizada através do número de estabelecimentos agropecuários que cultivam erva-mate. De acordo com os dados do CENSO AGROPECUÁRIO (2006) existem 15.750 estabelecimentos agropecuários no Brasil que cultivam erva-mate, considerando mais de 50 pés, sendo que 99,7\% destes estão no sul do Brasil. No estado do Rio Grande do Sul estão localizados 8.228 destes estabelecimentos; 4.468 no estado do Paraná e 3.005 em Santa Catarina.

Em relação à área colhida destes estabelecimentos, 51,6\% possuem até cinco hectares de erva-mate, sendo que no Rio Grande do Sul esse percentual aumenta para 55,8\%. No estado do Paraná 46,9\% dos estabelecimentos 
agropecuários que cultivam erva-mate colhem uma área de até cinco hectares, em Santa Catarina este percentual é de 47,1\%. Desta forma, 56,3\% da erva-mate vendida nos estabelecimentos agropecuários com mais de 50 pés existentes é proveniente de áreas inferiores a cinco hectares (IBGE, 2006). MACCARI JUNIOR et al., (2006) mencionam uma área média de exploração de erva-mate inferior a cinco hectares por estabelecimento agropecuário. De acordo com o agente 9, são pequenas áreas, mas a erva-mate é uma importante fonte de renda para os pequenos agricultores.

...são na maioria pequenos produtores, áreas de cinco, dez hectares, agricultura familiar mesmo, onde a erva-mate é uma fonte de renda importante [...] pagar o banco, quitar empréstimos, e até para comprar insumos para as outras culturas.

Estes dados demonstram a restrita disponibilidade de áreas cultiváveis nos estabelecimentos agropecuários que cultivam erva-mate. A maioria destes estabelecimentos utilizam-se da mão de obra familiar na produção, esta que é desenvolvida concomitantemente com outras atividades (OLIVEIRA \& WAQUIL, 2014). O agente 6 cita o surgimento de contratos de integração para produção de erva-mate no Paraná, o que caracteriza uma inovação organizacional no setor. O agente 1 menciona produtores no estado do Rio Grande do Sul que estão se especializado na produção de erva-mate, sendo esta a única fonte de renda da propriedade.

Muitos produtores visualizaram a possibilidade de agregação de valor no produto, adquirindo uma unidade de processamento e colocando sua marca no mercado. De acordo com os dados do SINDIMATE RS/PR e SC, no estado do Rio Grande do Sul existem 218 ervateiras, sendo que 60 delas estão concentradas no polo Alto Taquari, que compreende 11 municípios. No estado do Paraná são 140 ervateiras, enquanto em Santa Catarina esse número é de 80 empresas. Segundo os Sindicatos consultados, grande parte das ervateiras são pequenas empresas familiares, havendo poucas empresas líderes no setor.

No Rio Grande do Sul, a fragmentação do segmento industrial ervateiro foi retratado na década de 90 , sendo as principais características o pequeno porte, a inexistência de líderes no mercado e poucas barreiras de entrada (ANTONI, 1999). Mesmo não sendo o objetivo central, os dados desta pesquisa demonstram que a característica do pequeno porte das ervateiras e a inexistência de barreiras de entrada se mantém, não somente no Rio Grande do Sul, sendo a realidade também dos estados do Paraná e Santa Catarina.

A erva-mate beneficiada pelas ervateiras atende, em grande parte, o mercado interno, todavia, de acordo com OLIVEIRA \& WAQUIL (2014), a erva-mate beneficiada também é exportada para países como Chile, EUA e Alemanha. Já a erva-mate cancheada é principalmente exportada para o Mercosul, com destaque para o Uruguai, com aproximadamente $80 \%$ da erva-mate exportada. De 1990 a 2013, a média de exportação brasileira desta matéria-prima foi de 27.676,1 toneladas, enquanto de importações, no mesmo período, a média foi de 7.030 toneladas. No ano de 2013, 85,5\% da erva-mate exportadas teve como destino 0 mercado Uruguaio. Mesmo com grande destaque para o Uruguai, vem-se ampliando o número de países importadores da erva-mate brasileira. No ano de 1997 eram 17 países destino, chegando a 34 países em 2013 (FAO, 2015; MDIC, 2013). 


\section{CONCLUSÕES}

O cultivo da erva-mate e uma das atividades mais características da região sul do Brasil, apresentando importância socioeconômica e ambiental nos municípios onde ocorre. Apesar do protagonismo do estado do Rio Grande do Sul na produção da erva-mate, esse vem perdendo espaço, principalmente para o estado do Paraná. O crescimento da produção nesse estado ocorre principalmente pela preservação dos ervais nativos e sua contínua exploração, bem como de investimentos no setor, com destaque para o município de São Mateus do Sul, para a produção de ervamate envelhecida e o foco no mercado externo.

Por outro lado o Rio Grande do Sul, perdeu grande parte de seus ervais nativos com o advento da mecanização no campo, e a substituição desse cultivo por culturas anuais, principalmente nas áreas planas. Esse fato configurou a produção de erva-mate no estado em polos produtivos, com destaque para o polo do Alto Taquari e os municípios de llópolis e Arvorezinha, que aparecem entre os maiores produtores de erva-mate nacionais no período analisado. Destacando no estado a produção de erva-mate moída, e o foco principal no mercado interno.

Cultivada principalmente em pequenas propriedades rurais como uma fonte de renda alternativa, o setor ervateiro vem apresentando algumas alterações nos últimos anos. O registro de produtores especializados no cultivo de erva-mate no estado do Rio Grande do Sul, tendo a erva-mate como única fonte de renda, e contratos de integração entre ervateiras e produtores, no estado do Paraná, caracterizam inovações produtivas e organizacionais importantes no setor.

A partir dos dados consultados e as entrevistas realizadas com agentes ligados ao setor nos três estados do sul do Brasil, constatou-se que a dinâmica de produção de erva-mate sofreu alterações pela influência de outras atividades e fenômenos ocorridos no meio rural. Infere-se ainda que a cadeia produtiva da ervamate apresenta complexidades por se tratar de um mercado específico, ligado ao hábito e cultura dos consumidores, e pela ausência de mecanismos de regulação ou garantia de preço ao produtor, causando desequilíbrios na cadeia, o que merece estudos posteriores para uma análise aprofundada.

\section{REFERÊNCIAS}

ANTONI, V. L. A estrutura competitiva da indústria ervateira do Rio Grande do Sul. 1995. Teoria e Evidência Econômica, Passo Fundo, v. 7, n. 12, p. 49-68, maio, 1999.

APPOLINÁRIO, F. Metodologia da Ciência: filosofia e prática da pesquisa. São Paulo: Cengage Learning, 2011.

ASSOCIAÇÃO BRASILEIRA DE PRODUTORES DE FLORESTAS PLANTADA. Anuário estatístico da ABRAF 2013 ano base 2012. Brasília, 2013.

BALZON, D.R. SILVA, J. C. G. L. da; SANTOS, A. J. dos. Aspectos mercadológicos de produtos florestais não madeireiros - análise retrospectiva. Revista Floresta, v.34, n.3, p.363-371, 2004. Doi: http://dx.doi.org/10.5380/rf.v34i3.2422. Disponível 
em: <http://ojs.c3sl.ufpr.br/ojs/index.php/floresta/article/viewArticle/2422>. Acesso em: 25 mar. 2016.

FOOD AND AGRICULTURE ORGANIZATION OF THE UNITED NATIONS. FAOSTAT. Disponível em: <http://faostat3.fao.org/home/index.html\#COMPARE>. Acesso em: 04 mar. 2015.

GIL, A. C. Como elaborar projetos de pesquisa. 4. ed. São Paulo: Atlas, 2007.

IBGE, Instituto Brasileiro de Geografia e Estatística. Censo agropecuário, 2006. Disponível em: http://www.sidra.ibge.gov.br/bda/tabela/listabl.asp?z=t\&o=18\&i=P\&c=816>. Acesso em: 20 mar. 2015.

IBGE, Instituto Brasileiro de Geografia e Estatística. Produção Agrícola Municipal, 2014. Rio de Janeiro: IBGE. Disponível em: < http://www.sidra.ibge.gov.br/bda/tabela/protabl.asp?c=1613\&z=t\&o=1\&i=P>. Acesso em: 20 de mar. 2016.

MACCARI JUNIOR, A.; QUEIROZ, M. R.; RONCATO-MACCARI, L. D. B.; RUCKER, N. G. A. . Indústria ervateira no Estado do Paraná II - Fornecimento de matériaprima. Revista Acadêmica: Ciências Agrárias e Ambientais (PUC-PR. Impresso), v. 4 , n.1, p. 63-70, 2006.

MALHOTRA, N. K. Pesquisa de marketing: uma orientação aplicada. Porto Alegre: Bookman, 2010.

MEDRADO, M.J.S. A evolução do setor florestal brasileiro no século XXI, 2005. Online. Disponível em: <http://www.agrosoft.org.br/agropag/18698.htm>. Acesso em: 02 mar. 2013.

MINISTÉRIO DO DESENVOLVIMENTO, INDÚSTRIA E COMÉRCIO EXTERIOR. Exportações de commodities. 2013. Disponível em: $<$ http://www.mdic.gov.br/sitio/interna/interna.php?area=5\&menu=1955>. Acesso em 12 nov. 2015.

OLIVEIRA, S. V. de.; WAQUIL, P. D. Dinâmica de produção e comercialização de erva-mate no Rio Grande do Sul. Ciência Rural, Santa Maria, v.45, n.4, p.750-756, abr, 2015. Doi: http://dx.doi.org/10.1590/0103-8478cr20140276. Acesso em: 20 de mar. 2016.

OLIVEIRA, Y. M. M.; ROTTA, E. Área de Distribuição natural da erva-mate. In: SEMINÁRIO SOBRE ATUALIDADES E PERSPECTIVAS FLORESTAIS, 10., 1983, Curitiba. Anais... Curitiba: EMBRAPA/CNPFlorestas, 1985. p.17-36.1985.

RUCKER, N. G. A.; ORTIGARA, N. A. Pluralidades agroindustriais do setor ervateiro paranaense. Pesquisa de campo: Câmara Setorial Cadeia Produtiva Erva-mate do Paraná, 2003. 
SINDIMATE, Sindicato da Indústria do Mate do Estado do Rio Grande do Sul. Dados estatísticos. Disponível em: http://www.sindimaters.com.br/pagina.php?cont=estatisticas. php\&sel=9. Acesso em 26 mai. 2013.

TRIVIÑOS, A. N. S. Introdução à pesquisa em ciências sociais: a pesquisa qualitativa em educação. São Paulo: Atlas, 1987. 